\title{
Time for global action on Zika virus epidemic
}

\author{
Our response to infectious disease epidemics must be faster and smarter
}

\author{
Daniel R Lucey adjunct professor of medicine \\ Department of Medicine, Infectious Diseases, Georgetown University Medical Center, Washington, DC, USA
}

\begin{abstract}
After criticism that the World Health Organization responded slowly in 2014 to Ebola virus disease, and now to the epidemic of Zika virus disease, ${ }^{1}$ on 1 February 2016 WHO's director general, Margaret Chan, convened a meeting of the International Health Regulations Emergency Committee. After the meeting she declared Zika a public health emergency of international concern, because of the possible association with growing clusters of microcephaly and other neurological disorders in French Polynesia and Brazil. In less than a year this virus has spread to over 25 nations in the Americas, the Pacific islands, and Cape Verde in west Africa.

Faced with rapidly evolving concern among travelers, the public (particularly pregnant women and their partners), and the media, what are healthcare providers to do? Fortunately, they can provide accurate answers from several reliable sources, including Public Health England, ${ }^{2}$ the Pan American Health Organization, ${ }^{3}$ the US Centers for Disease Control and Prevention, ${ }^{4}$ and the European Centre for Disease Prevention and Control. ${ }^{5}$ Specific guidance for primary care has also been developed in the United Kingdom. ${ }^{6}$
\end{abstract}

Advice to travelers emphasizes basic measures such as cover-up clothing and insect repellant to protect against Aedes mosquitoes, which bite primarily during the day. ${ }^{2}$ Because of concerns about infection during pregnancy possibly causing congenital brain damage and microcephaly, Public Health England advises travelers who are pregnant to "consider avoiding travel to an area where active Zika transmission is being reported." ${ }^{2}$ Similar advice is provided by authorities in Canada, the United States, Australia, and Taiwan. Public Health England also advises that women, on returning to the UK, "should avoid becoming pregnant for a further 28 days." 2

The Zika virus was discovered in 1947 in a monkey in the Zika forest, Uganda. It is transmitted almost exclusively by mosquitoes of the Aedes genus, which cannot breed in the low temperatures common in the UK and other parts of northern Europe. ${ }^{2}$ Sexual transmission and transmission by blood transfusion have also been reported but remain rare. ${ }^{4}$ Public Health England advises that men returning from Zika risk areas use condoms for 28 days "if a female partner is at risk of getting pregnant, or is already pregnant." ${ }^{2}$ Men with a recent illness compatible with Zika virus disease should use condoms for much longer. ${ }^{2}$

The first Zika outbreaks associated with neonatal brain disorders and microcephaly occurred in 2013-14 in French Polynesia. The first Zika outbreaks in Brazil occurred in early 2015, and these were followed in October by an ongoing epidemic of microcephaly. Proof that Zika virus causes fetal microcephaly or other neurological abnormalities has not been established. Epidemiologic studies to track cases of microcephaly during 2016 are ongoing in Brazil and in countries affected later, such as Colombia.

The rapid spread of Zika virus in the Americas is thought to be due to the high density of Aedes mosquitoes in urban environments and the lack of any prior immunity. So far, no known mutation of the virus has been found to account for its spread or the possible link with neurologic disorders.

Typical clinical signs and symptoms of Zika virus disease include low grade fever, rash, joint and muscle pain, and conjunctivitis. These occur after a 3-12 day incubation period. Importantly, $80 \%$ of Zika virus infections are asymptomatic. Medical management is supportive only. No specific antiviral drugs are effective against Zika, and there is no vaccine. Diagnostic antibody tests can give false positive results because of cross reaction against related viruses such as dengue. No commercial diagnostic tests are available. On 3 February the UK Medical Research Council launched a rapid response to accelerate research into diagnostic tests, treatments, and vaccines.

In the $20 \%$ of patients who are symptomatic the clinical illness usually resolves in 2-7 days. Virus can be detected in the blood for 1-2 weeks by nucleic acid tests such as polymerase chain reaction. ${ }^{24}$ Fatal outcomes are rare. An association with neurological disorders such as Guillain-Barré syndrome, although not proved to be causal, has been reported in French Polynesia, Brazil, and El Salvador.

Coordinated operational leadership was lacking in the early stages of the Ebola epidemic in west Africa. We learnt many lessons from Ebola, but only those that are quickly translated to effective action will help us contain Zika. This time, our response must be faster and smarter-to control the Zika 
epidemic, and in preparation for the many other infectious disease epidemics surely to come.

Competing interests: I have read and understood BMJ's policy on declaration of interests and declare: None.

Competing interests and peer review: Commissioned; not externally peer reviewed.

For all The BMJs latest articles on the Zika virus epidemic go to bmj. co/zika.
1 Lucey D, Gostin L. The emerging Zika pandemic: enhancing preparedness. JAMA 27 Jan 2016, doi:10.1001/jama.2016.0904.

2 Public Health England. Health protection guidance: Zika virus. Updated 5 Feb 2016. www. gov.uk/guidance/zika-virus.

3 Pan American Health Organization. Zika virus. www.paho.org/hq/index.php?option=com_ content\&view=article\&id $=11585 \&$ ltemid $=41688 \&$ lang $=e n$.

4 Centers for Disease Control and Prevention. Zika virus. www.cdc.gov/zika.

5 European Centre for Disease Prevention and Control. Zika virus infection. http://ecdc. europa.eu/en/healthtopics/zika_virus_infection/pages/index.aspx.

6 Public Health England. Zika virus infection: guidance for primary care. 4 Feb 2016. https: //www.gov.uk/government/publications/zika-virus-infection-guidance-for-primary-care.

Cite this as: BMJ 2016;352:i781 